BMJ Open Sport \& Exercise Medicine

\section{Gender differences in mental health symptoms and risk factors in Australian elite athletes}

To cite: Walton CC, Rice S, Gao CX, et al. Gender differences in mental health symptoms and risk factors in Australian elite athletes. BMJ Open Sport \& Exercise Medicine 2021;7:e00984. doi:10.1136/ bmjsem-2020-000984

- Prepublication history and additional material is published online only. To view please visit the journal online (http://dx.doi. org/10.1136/bmjsem-2020000984).

Accepted 22 February 2021

\section{Check for updates}

(c) Author(s) (or their employer(s)) 2021. Re-use permitted under CC BY-NC. No commercial re-use. See rights and permissions. Published by BMJ.

${ }^{1}$ Elite Sports and Mental Health, Orygen, Melbourne, Victoria, Australia

${ }^{2}$ Centre for Youth Mental Health, The University of Melbourne, Melbourne, Victoria, Australia ${ }^{3}$ School of Public Health and Preventive Medicine, Monash University, Melbourne, Victoria, Australia

${ }^{4}$ Athlete Wellbeing and

Engagement, Australian Institute of Sport, Canberra, Australian Capital Territory, Australia

Correspondence to Dr Courtney C Walton; courtney.walton@orygen.org.au

\section{ABSTRACT}

Objectives To examine gender differences in the reporting of, and contributors to, mental health symptoms. Methods This was a cross-sectional observational study of adult athletes within a national elite sporting system $(n=523$; women $=292 ; 56 \%)$, who completed a battery of assessments including measures of mental health and adverse life events. Group differences across a range of scores were examined, followed by gender-stratified bootstrapped linear regression and meta-regression on measures where gender differences were observed.

Results Women athletes reported higher rates of mental health symptoms, and lower rates of mental well-being, although there were no differences in general psychological distress or life satisfaction. Women reported experiencing several adverse life events at higher rates than men; particularly interpersonal conflict, financial hardship and discrimination. Low self-esteem was consistently associated with poorer mental health outcomes for all athletes. While a range of factors were associated with poor mental health in men or women athletes, meta-regression suggested that experiencing financial difficulty and social media abuse were more uniquely associated with mental health symptoms in men. Conclusion Gender differences in mental health in elite athletes are apparent. Approaches to increasing well-being are required in elite sport.

\section{INTRODUCTION}

Limited attention has been paid to the role of gender in athlete mental health ${ }^{1}$ despite this being a major differentiating factor for rates across the general population. ${ }^{2}$ While recent studies have reported higher rates of mental health symptoms (MHS) in women athletes, ${ }^{3-5}$ our understanding of factors that contribute to this is incomplete. Additional to obstacles many women commonly face at work, ${ }^{6}$ women athletes may also experience stressors such as negative or sexualised perceptions of their body, ${ }^{7}$ unwanted social media messaging ${ }^{8}$ and financial difficulty. ${ }^{9}$ There is limited understanding of the association between such factors and MHS in elite sport.

\section{What are the new findings?}

While there were no gender differences in general psychological distress, life satisfaction or probable caseness for a mental health disorder, women athletes reported significantly higher rates of specific mental health symptoms than men.

- Women athletes reported experiencing a range of adverse life events at higher rates than men, including interpersonal conflict, financial hardship and discrimination.

- Low self-esteem presented as a highly important and consistent factor associated with poor mental health for all athletes. While a range of other factors were associated with mental health symptoms by gender, experiencing financial difficulty and social media abuse was associated with poorer mental health outcomes in men compared with women athletes.

This study provides descriptive data on the gender-based differences in a range of MHS across a sample of elite Australian athletes, and investigates specific contributing factors. We hypothesised that women athletes would report higher rates of symptomatology (eg, anxiety and mood, body image concerns) and that a range of adverse life experiences (ALEs) thought to occur more frequently in women athletes (eg, financial difficulty, discrimination) would contribute to these symptoms.

\section{METHODS}

Secondary analysis was undertaken on data from a previously described cross-sectional online survey. ${ }^{10}$

\section{Participants}

Athletes aged 18 years and over, who were supported by the Australian Institute of Sport (AIS) via being contracted with a national sporting organisation and had participated in an anonymous survey ${ }^{10}$ regarding their mental health and well-being. 


\section{Measures}

MHS were assessed using the 28-item General Health Questionnaire (GHQ-28), ${ }^{11}$ which provides a total score and scaled scores for (1) somatic complaints, (2) anxiety and insomnia, (3) social dysfunction and (4) severe depression. We examined continuous scale scores as well as potential 'caseness', in which those scoring six or more are considered to have a probable mental health disorder. ${ }^{12}$ Psychological distress was measured using the Kessler Psychological Distress Scale (K10). ${ }^{13}$ Self-esteem was measured using the Rosenberg Self-Esteem Scale. ${ }^{14}$ Well-being was assessed with the Warwick-Edinburgh Mental Well Being Scale. ${ }^{15}$ Body dissatisfaction was assessed using the weight and shape subscales from the Eating Disorders Examination Questionnaire. ${ }^{16}$ Two items ('How dissatisfied have you felt about your weight?' and 'How dissatisfied have you felt about your shape?') were averaged to create a single measure of body dissatisfaction as has been used in multiple studies. ${ }^{17}$ Risky alcohol consumption in the past 12 months was measured by the Alcohol Use Disorders Test. ${ }^{18}$ Life satisfaction was assessed using the Satisfaction with Life Scale. ${ }^{19}$

ALEs were assessed over the lifetime and previous year. Thirteen items were included, consisting of 'standard' life event questions and additional events encountered by athletes. Five questions examined the perceived availability, adequacy and sources of social support. ${ }^{20}$ Help-seeking for a personal or emotional problem was assessed using the General Help Seeking Questionnaire. ${ }^{21}$ More detail on these measures is included in online supplemental material 1.

\section{Statistical analysis}

Analysis was conducted in JAMOVI V.1.2.22, SPSS V.25.1 and R V.4.0.2 using the mixmeta package. ${ }^{22}$ Welch's t-tests were used to examine group differences on key continuous variables of interest due to their increased performance with or without violated parametric assumptions, with Cohen's d used to determine effect size. $\chi^{2}$ tests of association were used to determine between-group differences between categorical variables with $\mathrm{Phi}(\varphi)$ and Cramer's $V$ used to determine effect sizes. Gender stratified linear regression models were used to evaluate whether ALEs and other risk factors had different types of impact on MHS between men and women. As assumptions of normality and heteroscedasticity of residuals were not met for the linear model, conservative bootstrapping with 1000 resamples was employed. All models were established with a hierarchical method with relevant covariates entered first, followed by ALEs and body dissatisfaction, alcohol consumption, satisfaction with social support and self-esteem. We then used metaregression models (regression coefficients weighted by SEs were the dependent variable and gender as independent variable) to compare the statistical difference in the effect estimates between groups. The $p$ value of the metaregression indicates the level of evidence that risk factors impact on MHS differently between gender groups.

\section{Patient and public involvement}

The survey was developed in consultation with the AIS' Athlete Well-being and Engagement team, who consulted with former and current athletes in the study design.

\section{RESULTS}

\section{Participant characteristics}

Of 810 participants who initially responded to the survey, ${ }^{7}$ a sample of 523 was derived by excluding athletes with any missing data (ranging from 5\% for the GHQ to $14.85 \%$ for the SWLS; respectively the first and last measures in the survey). Descriptive data are provided in table 1 .

\section{General findings}

Table 2 provides scores by gender for the key measures. Our predictions were partially supported, though probable caseness was similar between groups (men $=29.0 \%$, women $\left.=34.6 \%, \chi^{2}=1.84, \mathrm{df}=1, \mathrm{p}=0.17, \varphi=0.59\right)$. No differences in psychological distress were observed. ALEs are provided in table 3 , with women athletes reporting more ALEs in total (men $\mathrm{M}=3.16, \mathrm{SD}=2.4$, women $\mathrm{M}=3.71$, $\left.\mathrm{SD}=2.6, \mathrm{t}_{\text {Welch }}=2.48, \mathrm{df}=510, \mathrm{p}=0.01, \mathrm{~d}=0.22\right)$. There were no differences in the likelihood of seeking help from those around them (men $\mathrm{M}=53.00, \mathrm{SD}=15.5$, women $\left.\mathrm{M}=52.30, \mathrm{SD}=14.1, \mathrm{t}_{\text {Welch }}=0.53, \mathrm{df}=470, \mathrm{p}=0.60, \mathrm{~d}=0.05\right)$, however, men reported more satisfaction with the support they received (men $\mathrm{M}=5.83, \mathrm{SD}=1.2$, women $\mathrm{M}=5.44$, $\left.\mathrm{SD}=1.4, \mathrm{t}_{\text {Welch }}=3.36, d f=520, \mathrm{p}=<0.001, \mathrm{~d}=0.29\right)$. Athletes prioritised personal relationships for support. Professionally, $7 \%$ of men and women athletes selected their sport psychologist as their primary source of support, with less than $2 \%$ selecting their coach.

\section{Regression models}

Eight models were evaluated across men and women athletes for the four GHQ-28 subscales. We included extracurricular work or study, a history of concussion and recent psychological treatment as covariates due to their significant difference by gender $($ at $p<0.05)$. Age was not included given that it did not differ between groups and was not correlated with any GHQ-28 subscales. Results from these regression models are displayed in figure 1 and online supplemental tables S1-2). Higher selfesteem was found to be a consistent protective factor of MHS across both genders. A range of other factors had more gender-specific involvement. Alcohol use was associated with increased anxiety/insomnia, and somatic complains in women but not men. Body dissatisfaction was found to be associated with anxiety/insomnia for men but severe depression in woman. Low satisfaction with social support was found to have a slightly more negative effect in women compared with men. The most significant gender differences, suggested by meta regression, were the experience of social media abuse (for social dysfunction and somatic complains) and financial hardship (for anxiety/insomnia and severe depression). These two factors were found to have a strong effect in men but not women. 
Table 1 Group descriptives

\begin{tabular}{|c|c|c|c|c|c|c|c|}
\hline & \multicolumn{6}{|c|}{ Test statistics } \\
\hline & & $\begin{array}{l}\text { Men } \\
(n=231)\end{array}$ & $\begin{array}{l}\text { Women } \\
(n=292)\end{array}$ & $\chi^{2}$ & $d f$ & P value & $\begin{array}{l}\text { Effect size } \\
(\varphi)\end{array}$ \\
\hline \multicolumn{2}{|l|}{ Age } & $24.5(8.43)$ & $23.76(6.27)$ & $-1.06^{*}$ & 415 & 0.29 & $.10 \dagger$ \\
\hline \multirow[t]{2}{*}{ Sexual orientation $\ddagger$} & Heterosexual & 225 (97\%) & 263 (90\%) & 11.1 & 1 & $<0.001$ & 0.15 \\
\hline & Non-heterosexual & $6(3 \%)$ & $29(10 \%)$ & & & & \\
\hline \multirow[t]{2}{*}{ Para-athlete status } & Para-athlete & $41(18 \%)$ & $35(12 \%)$ & 3.45 & 1 & 0.06 & 0.08 \\
\hline & Non-para athlete & $190(82 \%)$ & 257 (88\%) & & & & \\
\hline \multirow[t]{5}{*}{ Additional work } & None & $81(35 \%)$ & $92(32 \%)$ & 13.1 & 4 & 0.01 & $.16 \S$ \\
\hline & Voluntary & $11(5 \%)$ & $24(8 \%)$ & & & & \\
\hline & Casual & $62(27 \%)$ & $100(34 \%)$ & & & & \\
\hline & Part time & $35(15 \%)$ & $49(17 \%)$ & & & & \\
\hline & Full time & $42(18 \%)$ & 27 (9\%) & & & & \\
\hline \multicolumn{2}{|l|}{ Additional study } & $115(50 \%)$ & $175(60 \%)$ & 5.38 & 1 & 0.02 & 0.10 \\
\hline \multirow[t]{2}{*}{ Sport type } & Individual & $151(65 \%)$ & $173(59 \%)$ & 2.05 & 1 & 0.15 & 0.06 \\
\hline & Team & $80(35 \%)$ & $119(41 \%)$ & & & & \\
\hline \multicolumn{2}{|l|}{ Currently injured } & $26(11.2 \%)$ & $30(10.3 \%)$ & 0.13 & 1 & 0.72 & 0.02 \\
\hline \multicolumn{2}{|l|}{ Ever treated for a concussion } & 27 (12\%) & $54(19 \%)$ & 4.56 & 1 & 0.03 & 0.09 \\
\hline \multirow[t]{2}{*}{ Received psychological treatment } & Ever & $31(13 \%)$ & $80(27 \%)$ & 15.1 & 1 & $<0.001$ & 0.17 \\
\hline & $\begin{array}{l}\text { Within last } 12 \\
\text { months }\end{array}$ & $20(9 \%)$ & $78(27 \%)$ & 27.6 & 1 & $<0.001$ & 0.23 \\
\hline
\end{tabular}

However, due to the low proportion of athletes reporting a non-heterosexual orientation, we combined these responses in order to maintain confidentiality and limit the potential for identification of participants given the high profile sample.

${ }^{*} t_{\text {Welch }}$ used.

†Cohen's d.

$\ddagger W e$ are aware of the potentially negative effects regarding merging different minority identities into one category, as has been done here. However, due to the low proportion of athletes reporting a non-heterosexual orientation, we combined these responses in order to maintain confidentiality and limit the potential for identification of participants given the high profile sample.

$\S$ Cramer's $V^{d}$.

\section{DISCUSSION}

Our results are consistent with existing evidence that women athletes tend to report higher levels of MHS, ${ }^{3-5}$ though in our sample, the proportions meeting threshold for 'caseness' were somewhat similar. Women reported experiencing a range of ALEs at higher rates,

Table 2 Measures of mental health symptoms and well-being

\begin{tabular}{|c|c|c|c|c|c|c|}
\hline & \multirow{2}{*}{$\begin{array}{l}\text { Men } \\
\text { M (SD) }\end{array}$} & \multirow{2}{*}{$\begin{array}{l}\text { Women } \\
\text { M (SD) }\end{array}$} & \multicolumn{4}{|c|}{ Test statistics } \\
\hline & & & $t_{\text {Welch }}$ & Df & $P$ value & d \\
\hline GHQ-Total & $16.89(10.0)$ & $21.56(11.6)$ & 4.96 & 518 & $<0.001$ & 0.43 \\
\hline GHQ-Somatic complaints & $4.66(3.4)$ & $6.12(3.7)$ & 4.69 & 511 & $<0.001$ & 0.41 \\
\hline GHQ-Anxiety and insomnia & $4.35(4.3)$ & $6.26(4.7)$ & 4.84 & 513 & $<0.001$ & 0.42 \\
\hline GHQ-Social dysfunction & $6.73(2.5)$ & $7.41(2.8)$ & 2.93 & 517 & 0.00 & 0.25 \\
\hline GHQ-Severe depression & $1.14(2.6)$ & $1.76(3.1)$ & 2.49 & 521 & 0.01 & 0.21 \\
\hline Psychological distress & $16.08(5.3)$ & $16.68(6.1)$ & 1.19 & 516 & 0.23 & 0.10 \\
\hline Body dissatisfaction & $1.39(1.6)$ & $2.48(2.0)$ & 6.94 & 521 & $<0.001$ & 0.60 \\
\hline Alcohol use & $4.61(4.1)$ & $3.30(3.5)$ & 3.89 & 448 & $<0.001$ & 0.35 \\
\hline Self-esteem & $22.59(4.5)$ & $20.88(5.0)$ & 4.13 & 516 & $<0.001$ & 0.36 \\
\hline Mental well-being & $52.34(8.2)$ & $48.90(9.3)$ & 4.49 & 516 & $<0.001$ & 0.39 \\
\hline Satisfaction with life & $27.14(5.5)$ & $26.43(5.8)$ & 1.44 & 508 & 0.15 & 0.13 \\
\hline
\end{tabular}

GHQ, General Health Questionnaire. 
Table 3 The experience of negative life events in men and women elite athletes

\begin{tabular}{|c|c|c|c|c|c|c|}
\hline & & $\%$ Ex & ienced & Test s & istics & \\
\hline & & Men & Women & $\chi^{2}$ & $P$ value & $\varphi$ \\
\hline Serious illness or injury & Ever & 46.6 & 50.7 & 0.88 & 0.35 & 0.04 \\
\hline Serious illness or injury (of a close relative) & Ever & 53.0 & 51.4 & 0.14 & 0.71 & 0.02 \\
\hline & Last 12 months & 14.7 & 14.4 & 0.01 & 0.93 & 0.00 \\
\hline & Last 12 months & 16.4 & 13.0 & 1.18 & 0.28 & 0.05 \\
\hline Separation & Ever & 25.9 & 22.3 & 0.92 & 0.34 & 0.04 \\
\hline & Last 12 months & 6.9 & 8.2 & 0.32 & 0.57 & 0.02 \\
\hline Interpersonal conflict & Ever & 12.9 & 26.0 & 13.7 & $<0.001$ & 0.16 \\
\hline & Last 12 months & 3.0 & 7.5 & 5.05 & 0.03 & 0.10 \\
\hline Stalked by fan & Ever & 3.4 & 7.2 & 3.47 & 0.06 & 0.08 \\
\hline & Last 12 months & 1.7 & 2.1 & 0.08 & 0.78 & 0.01 \\
\hline Discrimination & Ever & 12.1 & 20.2 & 6.18 & 0.01 & 0.11 \\
\hline & Last 12 months & 1.7 & 7.5 & 9.25 & 0.00 & 0.13 \\
\hline Social media abuse & Ever & 9.9 & 16.1 & 4.27 & 0.04 & 0.09 \\
\hline & Last 12 months & 1.7 & 5.8 & 5.64 & 0.02 & 0.10 \\
\hline Victim of crime & Ever & 6.9 & 10.6 & 2.19 & 0.14 & 0.06 \\
\hline & Last 12 months & 0.9 & 2.4 & 1.81 & 0.18 & 0.06 \\
\hline Undervalued & Ever & 34.5 & 42.8 & 3.76 & 0.05 & 0.08 \\
\hline
\end{tabular}

particularly with regards to interpersonal conflict, financial hardship and discrimination. Men athletes reported higher rates of alcohol consumption, but also higher selfesteem and mental well-being and did not experience any ALEs at a higher rate than women. With regard to potential correlates of MHS, low self-esteem was a critical and consistent factor for MHS across all athletes. While a range of factors were significant for one gender only, meta-regression to compare these differences between gender suggested that experiencing financial hardship and social media abuse appeared to have a particularly negative effect on the mental health of men athletes. The results point towards potential avenues for early intervention and treatment approaches.

That men and women athletes reported equal levels of psychological distress and satisfaction with life, is somewhat at odds with the consistent pattern of higher rates of symptom reporting in women. As described by others, ${ }^{1}$ this may at least in part reflect differences around men's reporting, with men athletes being less likely to report the symptoms they experience. Male athletes may also experience distress in ways that are not captured by current gender neutral screening tools that fail to consider the role of socialisation. ${ }^{23}$ Such interpretations cannot be concluded, but should be considered, given relationships between masculinity and mental health stigma in sport. $^{24}$

A gender pay gap at the expense of women has been described in many areas of society, with major problems in sport well established. While financial difficulties were more commonly experienced by women athletes in our sample, they were conversely, more related to MHS in men. One interpretation is that men athletes may value financial security as more important to their well-being, given established associations between financial security/strain with masculinity. ${ }^{25}$ Similarly, despite more women athletes having experienced abusive messaging on social media, this form of abuse was more relevant to men's MHS. We are cautious in how to interpret such a finding. A provisional interpretation may be that men athletes in our sample were exposed to more 
(A)

(B)

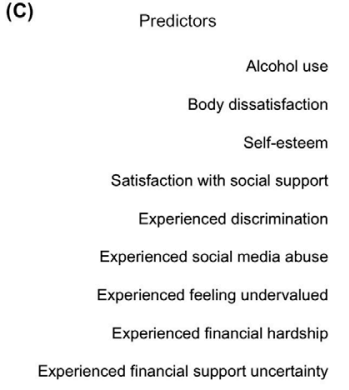

(D)

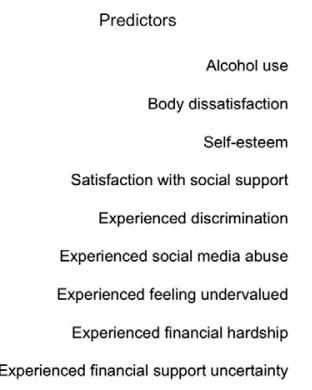

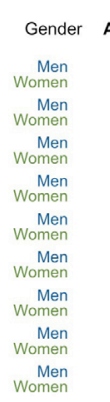

Anxiety \& Insomnia

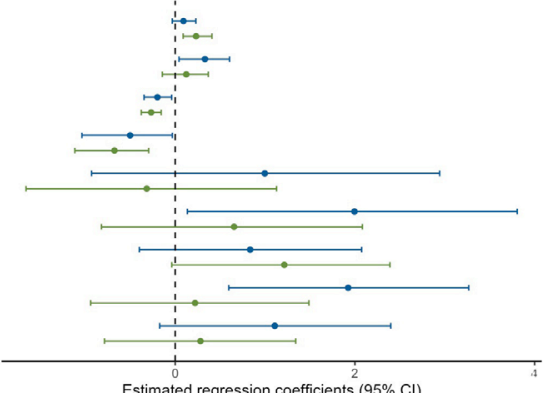

Estimated regression coefficients $(95 \% \mathrm{Cl})$

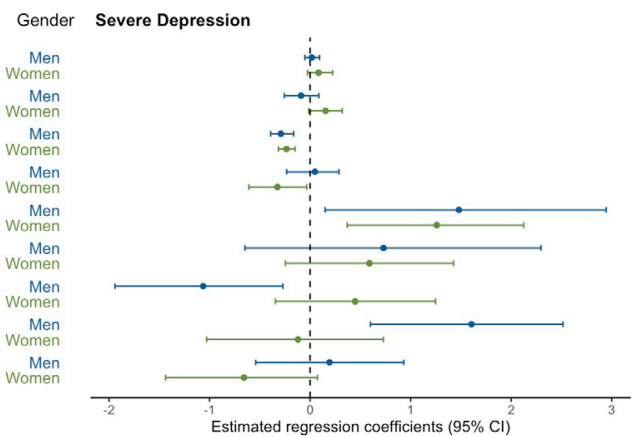

Gender Social Dysfunction
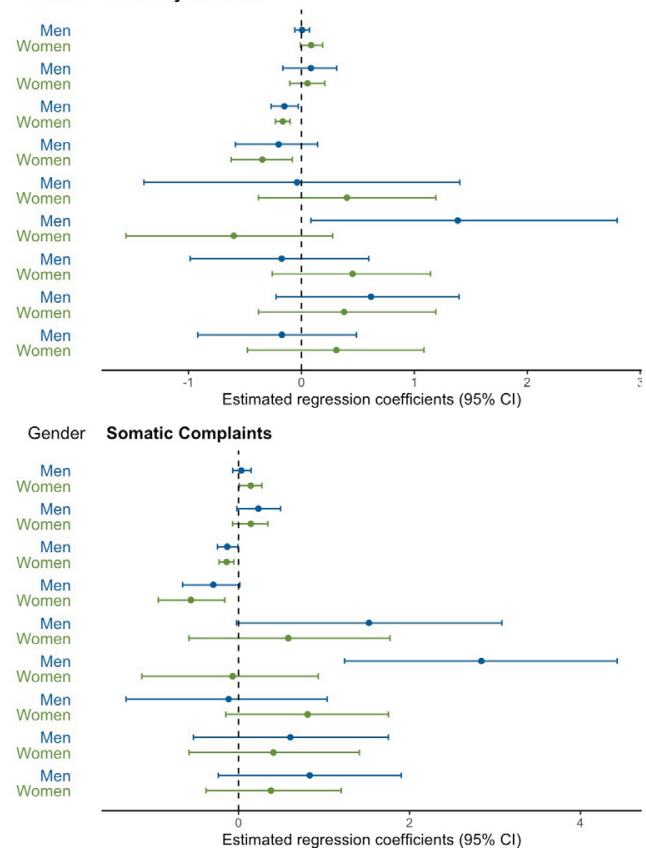

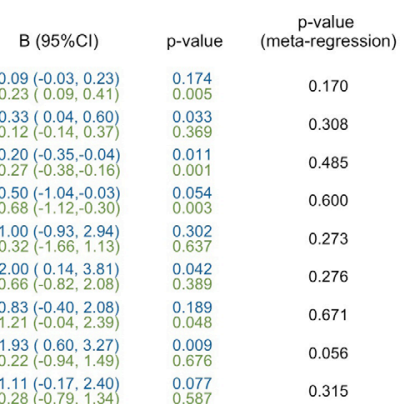

$\begin{array}{lll}1.11(-0.17 .2 .40) \\ 0.28(-0.79 .134) & 0.077 & 0.315\end{array}$

\begin{tabular}{|c|c|c|}
\hline B (95\%Cl) & $p$-value & $\begin{array}{c}p-\text {-value } \\
\text { (meta-regression) }\end{array}$ \\
\hline $\begin{array}{l}0.02(-0.05,0.09) \\
0.08(-0.03,0.22)\end{array}$ & $\begin{array}{l}0.587 \\
0.196\end{array}$ & 0.352 \\
\hline $\begin{array}{l}-0.09(-0.26,0.09) \\
0.15(-0.01,0.32)\end{array}$ & $\begin{array}{l}0.301 \\
0.058\end{array}$ & 0.040 \\
\hline $\begin{array}{l}-0.29(-0.39,-0.16) \\
-0.23(-0.32,-0.15)\end{array}$ & $\begin{array}{l}0.001 \\
0.001\end{array}$ & 0.406 \\
\hline $\begin{array}{r}0.05(-0.23,0.29) \\
-0.32(-0.61,-0.03)\end{array}$ & $\begin{array}{l}0.725 \\
0.027\end{array}$ & 0.060 \\
\hline $\begin{array}{l}1.48(0.15,2.94) \\
1.26(0.37,2.12)\end{array}$ & $\begin{array}{l}0.038 \\
0.008\end{array}$ & 0.794 \\
\hline $\begin{array}{l}0.73(-0.65,2.30) \\
0.59(-0.25,1.43)\end{array}$ & $\begin{array}{l}0.345 \\
0.230\end{array}$ & 0.878 \\
\hline $\begin{array}{l}-1.06(-1.94,-0.27) \\
0.45(-0.34,1.25)\end{array}$ & $\begin{array}{l}0.022 \\
0.300\end{array}$ & 0.013 \\
\hline $\begin{array}{l}1.60(0.60,2.52) \\
0.12(-1.03,0.73)\end{array}$ & $\begin{array}{l}0.007 \\
0.784\end{array}$ & 0.007 \\
\hline $\begin{array}{r}0.19(-0.54,0.93) \\
-0.66(-1.44,0.07)\end{array}$ & $\begin{array}{l}0.607 \\
0.068\end{array}$ & 0.090 \\
\hline
\end{tabular}

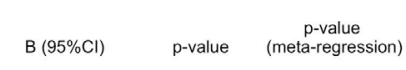

$\begin{array}{lll}0.01(-0.06 .0 .07) & 0.848 & 0.200\end{array}$

$\begin{array}{lll}0.08(-0.16,0.31) & 0.469 & 0.833\end{array}$

$\begin{array}{lll}-0.15(-0.27-0.03) & 0.009 & 0.840 \\ -0.16(-0.23,-0.10) & 0.001 & 0.84\end{array}$

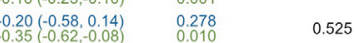

$\begin{array}{rrr}-0.04(-1.40,1.40) & 0.949 & 0.584 \\ 0.40 & (-0.38,1.49) & 0.383\end{array}$

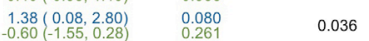

$\begin{array}{lll}-0.17(-0.98,0.60) & 0.653 & 0.254 \\ 0.45(-0.26,1.14) & 0.258 & 0.254\end{array}$

$\begin{array}{lll}0.62(-2.22,1.40) & 0.146 \\ 0.38 & 0.038 .1199 & 0.679\end{array}$

$\begin{array}{lll}-0.17(-0.92 .0 .49) & 0.625 & 0.35 \\ 0.31(-0.48,1.08) & 0.413 & 0.347\end{array}$

\begin{tabular}{|c|c|c|}
\hline B (95\%Cl) & $p$-value & $\begin{array}{c}\text { p-value } \\
\text { (meta-regression) }\end{array}$ \\
\hline $\begin{array}{l}0.03(-0.07,0.15) \\
0.14(0.01,0.27\end{array}$ & $\begin{array}{l}0.520 \\
0.032\end{array}$ & 0.187 \\
\hline $\begin{array}{l}0.23 \\
0.14(-0.02,0.49 \\
0\end{array}$ & $\begin{array}{l}0.089 \\
0.172\end{array}$ & 0.607 \\
\hline $\begin{array}{r}-0.13(-0.25,-0.01) \\
-0.14(-0.23,-0.06)\end{array}$ & $\begin{array}{l}0.021 \\
0.004\end{array}$ & 0.914 \\
\hline $\begin{array}{r}-0.30-0.65,0.01) \\
-0.56(-0.94,-0.16)\end{array}$ & $\begin{array}{l}0.127 \\
0.002\end{array}$ & 0.326 \\
\hline $\begin{array}{r}1.53 \\
0.58(-0.02,3.08) \\
0.0 .58,1.77)\end{array}$ & $\begin{array}{l}0.045 \\
0.323\end{array}$ & 0.334 \\
\hline $\begin{array}{r}2.84(1.24,4.43) \\
-0.07(-1.13,0.93)\end{array}$ & $\begin{array}{l}0.006 \\
0.907\end{array}$ & 0.007 \\
\hline $\begin{array}{r}-0.12(-1.32,1.04) \\
0.81(-0.15,1.75)\end{array}$ & $\begin{array}{l}0.828 \\
0.091\end{array}$ & 0.214 \\
\hline $\begin{array}{l}0.61 \\
0.41(-0.53,1.75)\end{array}$ & $\begin{array}{l}0.265 \\
0.408\end{array}$ & 0.788 \\
\hline $\begin{array}{l}0.83 \\
0.38(-0.24,1,190) \\
0.0 .38,1.20)\end{array}$ & $\begin{array}{l}0.151 \\
0.387\end{array}$ & 0.534 \\
\hline
\end{tabular}

Figure 1 Estimated associations between risk factors and outcomes by gender. All coefficients were estimated from multivariate bootstrapped linear regression model controlling for additional confounding factors; extracurricular work and study, a history of concussion and recent psychological treatment.

public social media abuse, given the problematic over-representation of men's sports coverage relative to women in the media. Nevertheless, we strongly encourage replication of these findings, given some results are in the opposite direction to that expected. Further research into the causes of gender differences in mental health in elite sport is needed more generally.

\section{Limitations}

The sample is large but not representative, reflecting $34 \%$ of athletes supported by the AIS. Also, participants only identified as binary genders. Many reasons may account for this lack of diversity, and it may reflect difficulties of gender diverse athletes competing at elite levels. ${ }^{26}$

\section{CONCLUSION}

Elite women athletes report MHS at a significantly higher rate than men athletes, though a series of caveats to this result must be considered. Elite sporting institutions are encouraged to monitor these factors, and to implement early intervention approaches to 
reduce exposure to potential risk factors within their organisations. Approaches to improving how both men and women athletes relate to self are indicated, with compassion-based techniques accepted within elite and masculine samples, and potentially suited to this approach. ${ }^{27-29}$

\section{Twitter Courtney C Walton @CC_Walton}

Acknowledgements We would like to thank all participants for being involved in this research.

Contributors CCW: concept, methodology, analysis, writing, editing. SR: concept, methodology, analysis, writing, editing. CG: analysis, writing, editing. MB: concept, methodology, editing. MC: concept, methodology, editing. RP: concept, methodology, analysis, writing, editing.

Funding CCW is supported by a McKenzie Postdoctoral Research Fellowship at the University of Melbourne (MCK2020292). SR is supported by a Career Development Fellowship from the National Health and Medical Research Council of Australia (APP1158881), and the Dame Kate Campbell Fellowship from the Faculty of Medicine, Dentistry and Health Sciences at The University of Melbourne.

Disclaimer The remaining authors have no funding to declare. The disclosed funding is not directly linked to this project and in no way influenced study design, collection, analysis, interpretation of data, writing of the report, or the decision to submit the paper for publication.

Competing interests Authors MB and MC are employed by the Australian Institute of Sport, which is funded by the Australian Sports Commission. Their involvement in the study included the survey design, data interpretation and contributions to the final draft manuscript, but not to the survey implementation or data analysis. The remaining authors have no conflicts of interest to declare.

Patient consent for publication Not required.

Ethics approval The research was approved by, and conducted in accordance with, the ethical standards of the University of Melbourne Human Ethics Research Committee (\#1442705).

Provenance and peer review Not commissioned; externally peer reviewed.

Open access This is an open access article distributed in accordance with the Creative Commons Attribution Non Commercial (CC BY-NC 4.0) license, which permits others to distribute, remix, adapt, build upon this work non-commercially, and license their derivative works on different terms, provided the original work is properly cited, appropriate credit is given, any changes made indicated, and the use is non-commercial. See: http://creativecommons.org/licenses/by-nc/4.0/.

ORCID iDs

Courtney C Walton http://orcid.org/0000-0003-0835-2310

Simon Rice http://orcid.org/0000-0003-4045-8553

\section{REFERENCES}

1 Poucher ZA, Tamminen KA, Kerr G, et al. A commentary on mental health research in elite sport. J Appl Sport Psychol 2021;33:60-82.

2 Seedat S, Scott KM, Angermeyer MC, et al. Cross-National associations between gender and mental disorders in the world Health organization world mental health surveys. Arch Gen Psychiatry 2009;66:785-95.

3 Schaal K, Tafflet M, Nassif H, et al. Psychological balance in high level athletes: gender-based differences and sport-specific patterns. PLoS One 2011;6:e19007.

4 Åkesdotter C, Kenttä G, Eloranta S, et al. The prevalence of mental health problems in elite athletes. J Sci Med Sport 2020;23:329-35.

5 Kuettel A, Pedersen AK, Larsen CH. To Flourish or Languish, that is the question: exploring the mental health profiles of Danish elite athletes. Psychol Sport Exerc 2021;52:101837.
6 Sojo VE, Wood RE, Genat AE. Harmful Workplace Experiences and Women's Occupational Well-Being: A Meta-Analysis. Psychol Women Q 2016;40:10-40.

7 Sherry E, Osborne A, Nicholson M. Images of sports women: a review. Sex Roles 2016;74:299-309.

8 Geurin AN. Elite Female Athletes' Perceptions of New Media Use Relating to Their Careers: A Qualitative Analysis. J Sport Manag 2017;31:345-59.

9 Bennie A, Walton CC, O'Connor D, et al. The post-Olympic games experience: a qualitative investigation of Australian Rio Olympians 2019.

10 Purcell R, Rice S, Butterworth M, et al. Rates and correlates of mental health symptoms in currently competing elite athletes from the Australian National high-performance sports system. Sports Med 2020;50:1683-94.

11 Goldberg DP, Hillier VF. A scaled version of the general health questionnaire. Psychol Med 1979;9:139-45.

12 Goldberg DP, Gater R, Sartorius N, et al. The validity of two versions of the GHQ in the who study of mental illness in general health care. Psychol Med 1997;27:191-7.

13 Kessler RC, Andrews G, Colpe LJ, et al. Short screening scales to monitor population prevalences and trends in non-specific psychological distress. Psychol Med 2002;32:959-76.

14 Rosenberg M. Society and the adolescent self-image: Princeton university press 2015 .

15 Tennant R, Hiller L, Fishwick R, et al. The Warwick-Edinburgh mental well-being scale (WEMWBS): development and UK validation. Health Qual Life Outcomes 2007;5:63.

16 Fairburn CG, Beglin SJ. Assessment of eating disorders: interview or self-report questionnaire? Int J Eat Disord 1994;16:363-70.

17 Griffiths S, Hay P, Mitchison D, et al. Sex differences in the relationships between body dissatisfaction, quality of life and psychological distress. Aust N Z J Public Health 2016;40:518-22.

18 Saunders JB, Aasland OG, Babor TF, et al. Development of the Alcohol Use Disorders Identification Test (AUDIT): WHO Collaborative Project on Early Detection of Persons with Harmful Alcohol Consumption--II. Addiction 1993;88:791-804.

19 Diener E, Emmons RA, Larsen RJ, et al. The satisfaction with life scale. J Pers Assess 1985;49:71-5.

20 Purcell R, Pathé M, Baksheev GN, et al. What mediates psychopathology in Stalking victims? the role of individualvulnerability and stalking-related factors. J Forens Psychiatry Psychol 2012;23:361-70.

21 Wilson CJ, Deane FP, Ciarrochi JV. Measuring help-seeking intentions: properties of the general help-seeking questionnaire. Can $J$ Couns 2005;39:15-28.

22 Sera F, Armstrong B, Blangiardo $\mathrm{M}$, et al. An extended mixed-effects framework for meta-analysis. Stat Med 2019;38:5429-44.

23 Rice SM, Parker AG, Mawren D, et al. Preliminary psychometric validation of a brief screening tool for athlete mental health among male elite athletes: the athlete psychological strain questionnaire. Int $J$ Sport Exerc Psychol 2020;18:850-65.

24 Steinfeldt JA, Steinfeldt MC. Profile of masculine norms and helpseeking stigma in college football. Sport Exerc Perform Psychol 2012;1:58-71.

25 Dyke LS, Murphy SA. How we define success: a qualitative study of what matters most to women and men. Sex Roles 2006;55:357-71.

26 Jones BA, Arcelus J, Bouman WP, et al. Sport and transgender people: a systematic review of the literature relating to sport participation and competitive sport policies. Sports Med 2017;47:701-16

27 Walton CC, Baranoff J, Gilbert P, et al. Self-compassion, social rank, and psychological distress in athletes of varying competitive levels. Psychol Sport Exerc 2020;50:101733.

28 Mosewich AD, Ferguson LJ, McHugh T-LF, et al. Enhancing capacity: integrating self-compassion in sport. J Sport Psychol Action 2019;10:235-43.

29 Reis NA, Kowalski KC, Mosewich AD, et al. Exploring SelfCompassion and versions of masculinity in men athletes. $J$ Sport Exerc Psychol 2019:368-79. 